(Previously Prace Naukowe Instytutu Gornictwa Politechniki Wroclawskiej, ISSN 0370-0798)

ISSN 2300-9586 (print)

ISSN 2353-5423 (online)

Received November 22, 2019; reviewed; accepted September 16, 2020

\title{
UNIVERSAL APPROACH \\ FOR RISK IDENTIFICATION AND EVALUATION IN UNDERGROUND FACILITIES
}

\author{
Witold PYTEL ${ }^{1}$, Krzysztof FUŁAWKA ${ }^{2 *}$, \\ Bogumiła PAŁAC-WALKO ${ }^{1}$, Piotr MERTUSZKA ${ }^{2}$, Jan KISIEL ${ }^{3}$, \\ Panu JALAS ${ }^{4}$, Jari JOUTSENVAARA ${ }^{4}$, Vitali SHEKOV ${ }^{5}$ \\ ${ }^{1}$ Wrocław University of Science and Technology, Wrocław, Poland \\ ${ }^{2}$ KGHM CUPRUM Ltd. Research \& Development Centre, Wrocław, Poland \\ ${ }^{3}$ University of Silesia, Katowice, Poland \\ ${ }^{4}$ University of Oulu, Oulu, Finland \\ ${ }^{5}$ Karelian Research Centre of the Russian Academy of Sciences, Russia
}

\begin{abstract}
Underground laboratories provide a unique environment for various industries and are the perfect place for developing new technologies for mining, geophysical surveys, radiation detection as well as many other studies and measurements. Unfortunately working in underground excavations is associated with exposure to many hazards not encountered in the laboratories located on the surface. Water inflow, gas burst, roof fall and even seismic hazards translate into high accident rates in the underground mining industry across the globe. Therefore, to minimise the risk of serious accidents, a lot of research investigations related to the development of effective risk assessment procedures are being carried out. One of the initiatives aimed at improving the work safety in underground laboratories in the Baltic Sea Innovation Network project implemented under the Interreg Baltic Sea Region Programme. This study presents the process of compiling a database on hazards within underground laboratories. Finally, a proposal of unification of the procedure for risk assessment, including methods for determining the likelihood and potential impact of unwanted events has been developed.
\end{abstract}

Keywords: risk assessment; risk matrix; numerical modelling; underground laboratory

* Corresponding author: kfulawka@cuprum.wroc.pl (K. Fuławka)

doi: 10.37190/MSC202712 


\section{INTRODUCTION}

Underground laboratories due to their unique environment are characterised by high research, educational and touristic potential. Apart from the development opportunities of mining technologies in the environment corresponding to real working conditions, underground laboratories are a suitable place for various types of geophysical surveys, radiation detection or radioactive waste disposal. Unfortunately working in underground excavations is inherently associated with a high level of risk, related to both natural and technical hazards as well as technological problems (Martyka 2015; Groves et al. 2007). The scale of hazard depends on many factors. One of the key elements affecting the level of safety in underground laboratories' operation is their depth below the surface, as the geomechanical hazard growths with its increase (Li et al. 2007). The problem of the presence of fumes and explosive gases in the mine atmosphere, the size of the mined-out area in the vicinity of active underground workings (Fuławka et al. 2018) and the distance of workings from the fault-affected zones is also of practical significance (Zorychta and Burtan 2012). As a result, the mining industry, which undoubtedly includes underground research laboratories, is associated with a relatively high incident rate.

According to a report by The National Institute for Occupational Safety and Health of the US, only in the United States, as many as 726 mining disasters occurred in the years 1900-2016 in underground mining. These disasters have resulted in more than 12,800 casualties among the miners during the recorded period (CDC, 2018). The situation in underground mines in Europe and Asia is also not encouraging, as, since the beginning of the 21st century, several dozen mining accidents have been recorded there, resulting in several hundred deaths.

Despite the strong emphasis on the training of mining personnel in occupational safety and the use of preventive measures, the incident rate in the mining industry remains at a very high level (Sanmiquel et al. 2010; Dhillon 2010; Komljenovic et al. 2008). This problem concerns almost all underground facilities, as even under good geomechanical conditions, there are still other kinds of hazards related to lighting, watering, ventilation, etc. (Galvin 2017). Therefore, to improve occupational safety in the mining industry, and consequently, in underground laboratories, a number of research works are being carried out around the world, focused on minimising or preventing these hazards.

The first step, crucial from the safety point of view is proper identification and classification of possible unwanted events. It is of high importance especially in cases where establishing a new underground facility, e.g., in abandoned mine is considered, by an external entity, which may be not fully aware of possible risk.

In this study, selected methods of risk assessment were described and their applicability at the stage of design, construction and operation of underground laboratories was defined. Data on possible risks in underground laboratories are presented and 
assigned to individual categories. Also, the preliminary risk assessment for underground laboratories of BSR region was conducted. As a result, unified procedures for hazard identification and risk assessment in underground research laboratories were developed.

\section{THE UNDERGROUND LABORATORIES IN BSR}

In order to identify, evaluate and finally mitigate the risk surveys concerning hazard evaluation in ULs of Baltic sea region were conducted. Risk database was discussed and completed with supervisors of underground laboratories of the research and development sector (Callio Lab from Finland, Äspö HRL from Sweden, Reiche Zeche from Germany, UL of Khlopin Institute, Russia) and laboratories intended mainly for tourist purposes (Ruskeala, Russia). Also, the history of accidents observed in Polish underground mines was examined. In result even most rigorous assumptions were analysed added to the database. The locations of the underground laboratories involved in the risk identification process are shown in Fig. 1.

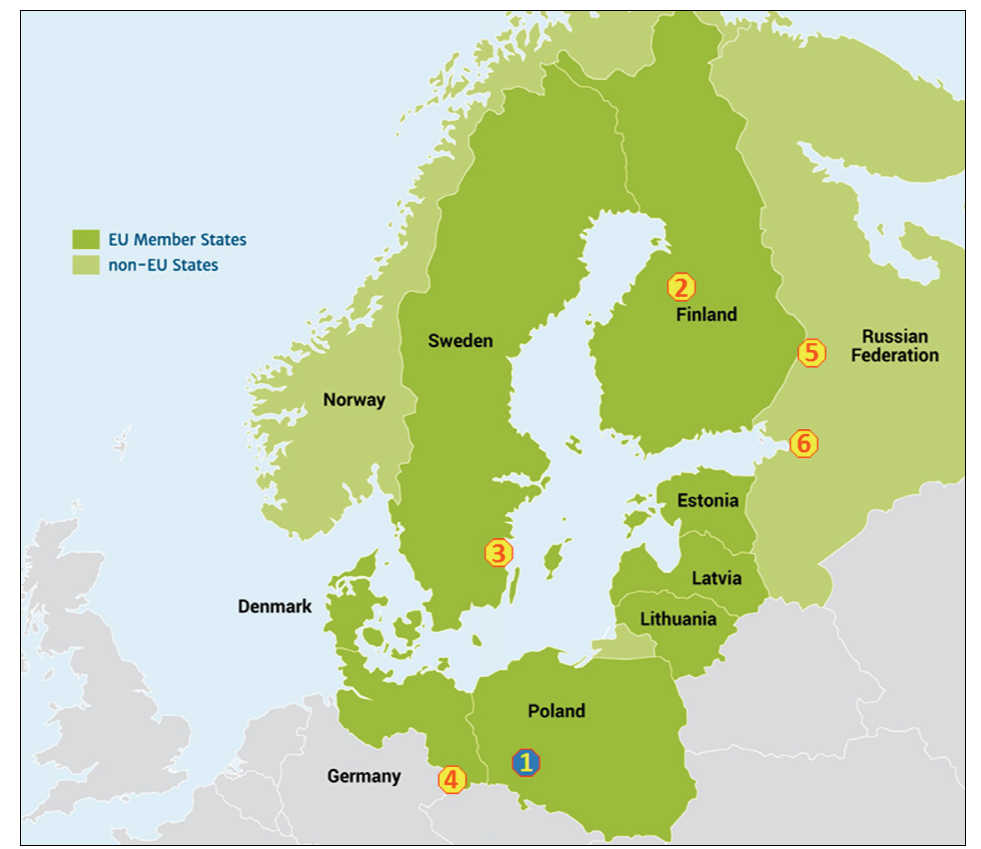

1 - KGHM underground copper mines, Poland; 2 - Callio Lab, Pyhäsalmi mine, Finland; 3 - Äspö Hard Rock Laboratory, Oskarshamn, Sweden; 4 - Reiche Zeche, TU Freiberg Research and Education mine, Germany; 5 - Ruskeala, Russia; 6 - Khlopin Institute Underground Laboratory, Russia

Fig. 1. Underground Laboratories in the Baltic Sea Region 


\section{REVIEW OF RISK ASSESSMENT METHODS}

As noted by Shooks et al. (2014), according to international standard IEC/FDIS 31010 Risk management - Risk assessment techniques (2009), a comprehensive risk assessment should include:

- Risk identification (definition of the type of hazard),

- Risk analysis (determination of frequency/probability of occurrence and possible consequences),

- Risk assessment (whether it is acceptable and if can be minimised).

Still, the risk is a very broad concept, and it is difficult to define it unequivocally, as evidenced by the multitude of definitions in world literature. According to the International Organization for Standardization (ISO), the risk is the effect of uncertainty on objectives (ISO Guide 73:2009). For industry, the definition that risk is the product of frequency and severity of events is often used (Suddle 2009; Aven 2010). Whereas in economic analyses risk is described as a mathematical concept in the form of expected consequences, both in terms of losses and profits (UNISDR, 2004). The definition proposed by Fenton and Griffiths (2008) that risk is the product of the probability of failure and the cost of its consequences is also widely used.

However, due to the multitude of hazard categories in underground research laboratories, for this study, the authors used the definition which states that risk is the result of probability multiplied by consequences of an unwanted event, also a failure, occurrence:

$$
R I S K=R P \times R I
$$

where:

$R P$ - the value of the probability of occurrence of an unwanted event,

$R I$ - consequences of the event, most often expressed by financial measures.

This is a universal approach applicable in assessing the risk of underground laboratories' operation, as it enables the risk to be presented in both cost or dimensionless form. Unfortunately, estimating the degree of probability and possible consequences of individual events occurrence is also a highly complex issue. It depends mostly on the quantity and quality of input data used in the analysis. In general, risk assessment methods can be divided into quantitative and qualitative.

\subsection{QUALITATIVE ANALYSIS}

Qualitative methods are very efficient in terms of economy and are characterised by high ease of implementation (Curtis and Carey 2012; Vardar et al. 2018). At the same 
time, they may be used as a preliminary method with the joint determination of risk occurrence probability against the potential severity of the analysed event. The estimation of both parameters is usually based on a survey or questionnaire. As a result, the estimation is rather based on the subjective assessment of employees what could be sort of disadvantage (Smolarkiewicz et al. 2011). However, the essential benefit of this method, is the ability to relatively quick characterise the risks which are the most dangerous. Consequently, it is possible to prioritise individual events from the least to the most dangerous. Recently few methods of qualitative analysis are in use among which the most popular are:

- Delphi Technique - method of risk assessment based on brainstorming of experts with deep knowledge about the examined issue, What is important experts can review experts notes, and during all process, some consensus should be reached.

- Structured What-If Technique (SWIFT) - this method uses a systematic, team-based evaluation of each risk in the form of a workshop. During risk assessment process effect or impact of different hypothetical situations in analysed with use "What if" considerations.

- Decision Tree Analysis - approach close to Event Tree Analysis, but without quantitatively presenting the result. In most cases, this method has been used to determine the best way to achieve a goal with the lowest level of risk.

- Bow-tie Analysis - in this method each risky event is examined in two directions. One branch describes all the potential causes of the event. In turn, in the second branch potential consequences are listed. In result, it is possible to identify risk and apply prevention solution to minimise hazard.

- Risk Matrix - At the moment this is the most commonly utilised approach in establishing risk severity. One of the most frequently used techniques of qualitative risk assessment is the method based on the so-called two-dimensional risk matrix (Fig. 2). In result, it is possible not only to determine the impact of each event but also identify how the risk is affected by its probability or consequence. This information is of high importance, during the process of mitigations procedures development (PMI, 2013). The risk assessment method based on a risk matrix for underground laboratories can be applied already at the design stage of a given facility. The assessment must be carried out exclusively by specialists in a particular field. Only a thorough and critical analysis allows identifying those aspects of the activity which involve a high level of risk. The assessment enables the early implementation of appropriate preventive and risk minimisation measures. At the same time, there are no technical limitations to use it as the basic method of classifying selected events as part of the periodic risk assessment of the operation of underground facilities throughout their entire life cycle. 


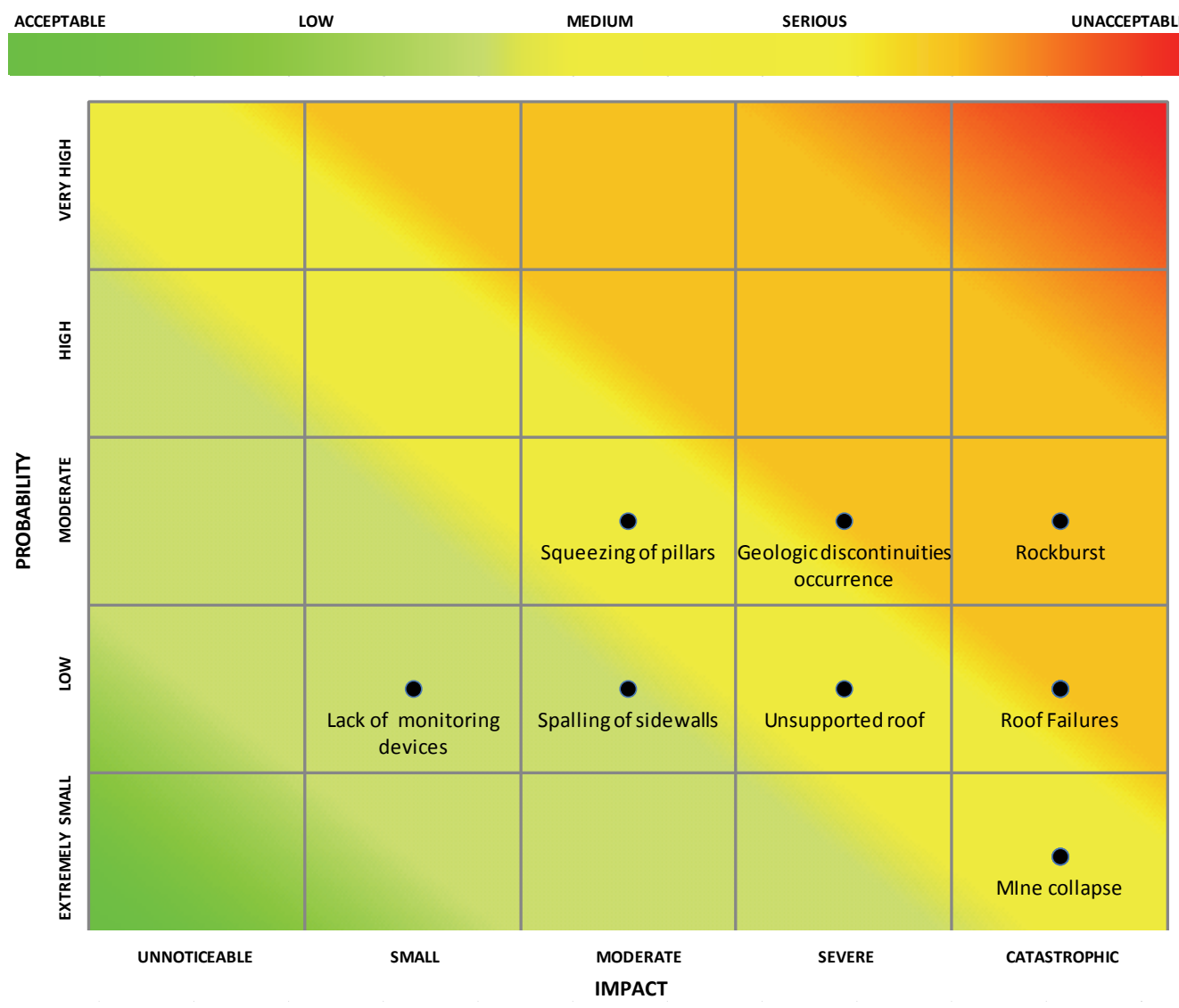

Fig. 2. Example of a $5 \times 5$ risk matrix

\subsection{QUANTITATIVE ANALYSIS}

The second group of methods includes so-called quantitative methods, which are usually based on statistical and numerical calculations. Quantitative methods are much more reliable than qualitative methods, as they are not directly based on subjective evaluation of the personnel involved in the analysis. Unfortunately, in order to carry out this kind of risk analysis properly, access to a large amount of detailed data on the examined facility or event is required.

One of the quantitative methods of risk assessment is probabilistic analysis. In many numerical simulation software using, e.g., DEM, FEM and LEM methods, probabilistic analysis allows to estimate the probability of, e.g., loss of stability of underground excavations, while taking into account the uncertainty and variability of model input parameters. The probabilistic risk assessment method of this type is widely used 
in geotechnical (Park et al. 2005; Zennir et al. 2011) and geomechanical analyses all over the world (Idris et al. 2011; Szurgacz 2015; Ghorbani et al. 2017). Numerical models of underground workings utilized in these analyses can be formulated as 2- or 3-dimensional (Fig. 3) problem, depending on the requirements and local geomechanical and mining conditions.
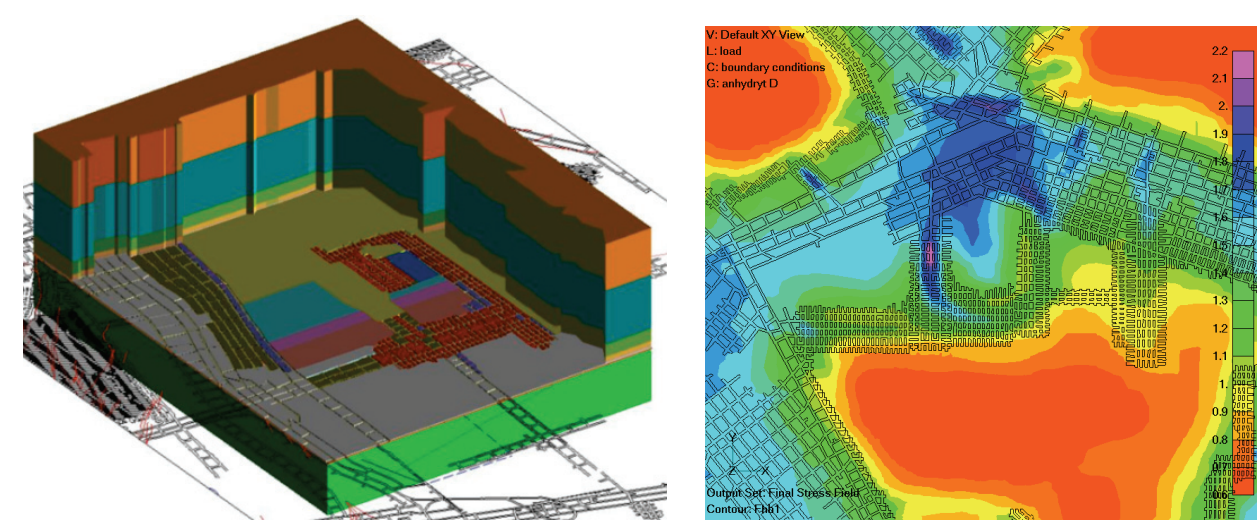

Fig. 3. The geometry of 3D FEM-based numerical model of underground excavations (left) with predicted changes of safety margins within the analysed area (right)

Numerical models allow determining the range of a hazard and possible consequences. Therefore, the numerical analysis combined with probabilistic analysis shall be required at the design stage of the ULs life cycle either. Moreover, for safety purposes, this kind of analyses should be conducted periodically, as the conditions ensuring the stability of excavations are crucial for this type of facilities.

Of course, numerical tools are not fully useful to determine the risk of all types of events. In the case of events related to, e.g., fires or traffic accidents, it is possible to use the so-called incident rates, which allow determining the frequency of an incident and its effect expressed in the time of inability to work.

The incident rate $\left(I_{R}\right)$ should be calculated in relation to working time according to the formula (OSHA, 2018):

$$
I_{R}=\frac{N_{c} \cdot 200,000}{N_{E l h}}
$$

where: $I_{R}$ - incident rate, $N_{c}$ - number of recorded cases, $N_{E l h}$ - the number of employee labour hours worked, hours.

The number of 200,000 in the formula refers to the number of hours worked in a year by 100 employees ( 100 employees $\times 40$ hours per week $\times 50$ weeks per year).

The incident rate may also be calculated in relation to the number of employees. For every 1,000 employees, $I_{R}$ is calculated, e.g. from the formula: 


$$
I_{R}=\frac{N_{c} \cdot 1,000}{N_{E}}
$$

where $N_{E}$ - the number of employees.

Calculated incident rates can be used to define the probability of an incident according to the relationship (Rothman 2002):

$$
P_{o I}=1-e^{\left(-I_{R} \cdot T\right)},
$$

where: $P_{o I}$ - probability of an incident, $I_{R}$ - calculated incident rate, $T$ - time, year.

Based on the above, the probability of an incident will increase over time as well as with the increase in the incident rate.

To determine the risk of complex events resulting from the overlapping of several negative factors, the "event tree" method may be used. This method is applicable to identify all elements that can initiate a series of consecutive events (branch of a tree) leading to specific consequences (Clemens 1998). Each case within a branch of tree must have a certain probability of occurrence. The product of successive probabilities is the resultant probability of the occurrence of a specific sequence of events (Clifton and Ericson, 2015). In terms of underground laboratories' operation, the event tree method should be used especially to assess the risk of complex events, e.g. when analysing the rockburst hazard. It enables the simultaneous consideration of the probability of a high energy tremor and the occurrence of excavation instability as a result of the dynamic seismic event (RocScience 2018).

Failure Mode and Effects Analysis (FMEA) and Failure Mode, Effects and Criticality Analysis (FMECA) can also be used to assess the risk of underground laboratories' operation. The FMEA method is used to identify potential mechanisms of facility failure and to estimate their consequences. This kind of analysis is based on the information on the object construction, the type of operation and the strategy for the development of underground workings included in the design documentation. In turn, the FMECA method is additionally extended by a semi-quantitative classification of destruction mechanisms based on the frequency of particular events occurrence and severity of their consequences (IEC, 2006).

The reliability of risk assessment depends mainly on the involvement of qualified experts from different fields related to the considered facility. From the geomechanical point of view, the most important is the knowledge on the depth and geometry of underground excavations, the development plans, induced seismicity level and the strength parameters of the surrounding rocks. The issues related to monitoring and observation of the rock mass condition and the environmental impact of a facility are also important. Selection of the optimal risk analysis method depends on the quality of input data. Basically, a comprehensive risk assessment for underground laboratories' should always begin with qualitative analysis to define the events that have a key impact on 
occupational safety. Then a quantitative analysis should be performed in particular for events with a potentially high risk.

\section{IDENTIFICATION OF POSSIBLE UNWANTED}

Within the framework of this study information regarding the risks in Polish coal mines (reports of the State Mining Authority) and Polish copper mines (hazard catalogue of KGHM Polska Miedź S.A.) were collected. As a result, a group of hazards associated with the operation of laboratories located in the vicinity of active mine workings were defined. The database has also been supplemented with information from underground laboratories supervisors (Fig. 4).

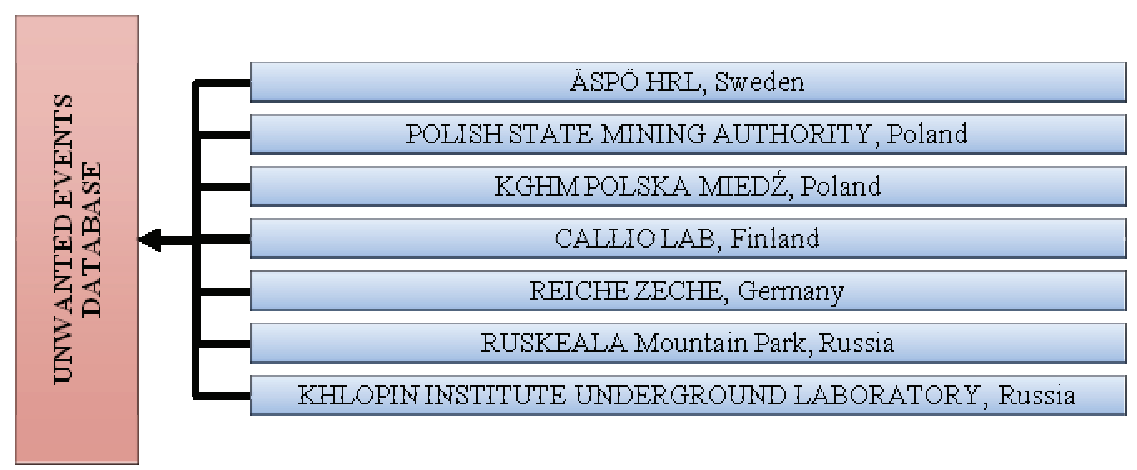

Fig. 4. BSR units taking part in the identification of risks in underground laboratories

Individual hazards were assigned to one of the four groups (Fig. 5) taking into account their origin, including:

- The first group called Environmental Risks is related to hazards of natural origin. The risks listed in this group are characterised by a negative impact on the working environment and are difficult to be prevented or eliminated. In this group, such events like seismic tremors, rock bursts, water inrush and the explosion of gases should be mentioned. The occurrence of one of the abovementioned events always generate a significant threat and may result in underground workings destruction or even fatalities. Therefore, monitoring of selected parameters is crucial from the risks minimization point of view.

- The second group described as Risk At The Workplace is directly related to the working environment and the technologies applied. Most of the risks in these group can be defined as common risks, which also exist in other industrial sectors, usually not resulting in fatalities, but implying a risk of occupational dis- 
eases. Still, in underground conditions, such factors like dust, vibration and lightning issues are much more harmful in comparison to activities conducted at the surface and thus comprehensive monitoring and periodical assessment need to be utilised in a regular manner.

- The risks belonging to the third group are related to mining operations and research activities in underground environment. Exploitation and tests of huge machines and use of explosives may be related to a great threat of an accident. When a hazard occurs, the consequences can often be very serious (fatalities). However, in the case of comprehensive monitoring of hazards as well as good work organisation and the application of preventive measures, the risk associated with the operation of underground workings can be effectively limited.

- The last group of hazards has been defined as OTHER. The risks of this type usually are not strictly related with the exploitation of underground laboratory and do not pose a severe threat to employees, but they may have a significant impact on the socio-economic aspects of the facility's operation. These risks are most often caused by external factors, which makes it difficult to prevent. Among such risks, some legal and social issues should be mentioned. In the example there is a risk that the local community, for various reasons, will not support all activities in the underground environment, due to the belief that the mining industry is highly harmful to the environment. In such a case, the entire project may be in danger of failure.

\section{I - ENVIRONMENTAL RISKS}

Ground Control

Seismic Activity

Water

Gases

Radiation

\section{II - RISK AT THE WORKPLACE}

Noise

Vibration

Lightening and Electric

Technological

Infrastructure related risk

\section{RISK IN UNDERGROUND}

LABORATORIES

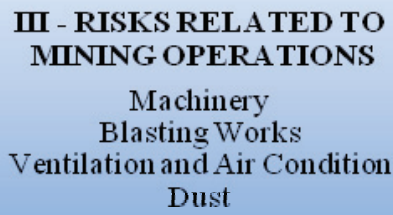

Fig. 5. Classification of identified risks by source

Based on the above, more detailed analysis was performed and included 106 hazards which were defined and divided into 18 hazard categories (Fig. 6). 


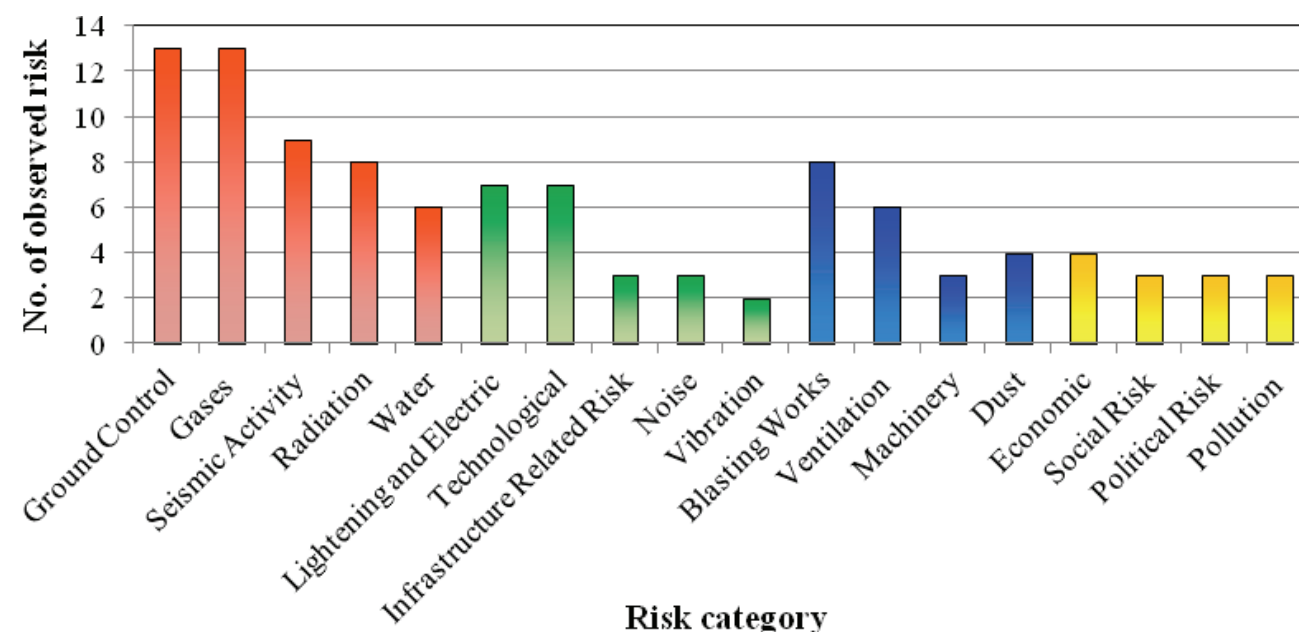

Fig. 6. Summary of identified risks in particular categories of hazard

In the quantitative domain, most of the risks are related to the so-called natural hazards (red bars). In this group, more than $46.6 \%$ of all categorised hazards were defined. Almost two times fewer hazards were observed in categories II - Risk At The Workplace (20.9\%) and III - Risks Related To Mining Operations (20.1\%) marked in green and blue, respectively. The smallest group of threats (12.4\%) turned out to be socio-economic threats marked in yellow.

In the next step, the risk was estimated by defining the probability and consequences of individual events. Based on the created database, each unwanted event was categorised and evaluated (Fig. 7). The preliminary risk assessment was conducted with representatives of underground laboratories from BSR and rock mechanics specialists knowing the risks observed in deep underground mines. As a result, detailed data on the distribution of the level of hazards related to unwanted events in particular categories were obtained. Figure 9 shows the percentage of events classified into subsequent risk groups. All events were considered separately for each category. For example, among all identified events in the Gases category, $66.67 \%$ of events were associated with a medium level of risk, while $28.57 \%$ with the low risk and $4.76 \%$ with the acceptable risk level

The number of observed risks depends strongly on the scale of the underground facility and its core activity. In the example, small facilities, which are settled in hard rocks, and does not utilise explosives during the lifecycle, are less affected by seismicity in comparison to Underground Labs located near to active mine. Still, there was the assumption that risk analysis should be conducted in a rigorous manner. Therefore, all experts, from each site, were asked to determine the probability and impact of all 106 hazards. 
Percentage of risk in each category [\%]

$\begin{array}{lllllllllllllllll}0 & 5 & 10 & 15 & 20 & 25 & 30 & 35 & 40 & 45 & 50 & 55 & 60 & 65 & 70 & 75\end{array}$

\begin{tabular}{|c|c|c|c|c|c|c|c|}
\hline \\
\hline & & Unacceptable & Serious & Medium & Low & Acceptable & Total \\
\hline \multirow{5}{*}{$\begin{array}{c}\text { ENVIRONMENTAL } \\
\text { RISKS }\end{array}$} & Ground Control & $0,00 \%$ & $24,00 \%$ & $52,00 \%$ & $20,00 \%$ & $4,00 \%$ & $100,00 \%$ \\
\hline & Gases & $0,00 \%$ & $\mathbf{0 , 0 0 \%}$ & $66,67 \%$ & $28,57 \%$ & $4,76 \%$ & $100,00 \%$ \\
\hline & Seismic Activity & $0,00 \%$ & $40,00 \%$ & $13,33 \%$ & $20,00 \%$ & $26,67 \%$ & $100,00 \%$ \\
\hline & Radiation & $0,00 \%$ & $\mathbf{0 , 0 0 \%}$ & $16,67 \%$ & $50,00 \%$ & $33,33 \%$ & $100,00 \%$ \\
\hline & Water & $0,00 \%$ & $5,88 \%$ & $23,53 \%$ & $52,94 \%$ & $17,65 \%$ & $100,00 \%$ \\
\hline \multirow{5}{*}{$\begin{array}{l}\text { RISK AT THE } \\
\text { WORKPLACE }\end{array}$} & Lighte ning and Electric & $0,00 \%$ & $8,00 \%$ & $24,00 \%$ & $28,00 \%$ & $40,00 \%$ & $100,00 \%$ \\
\hline & Technological & $0,00 \%$ & $3,57 \%$ & $7,14 \%$ & $75,00 \%$ & $14,29 \%$ & $100,00 \%$ \\
\hline & \begin{tabular}{|l|} 
Infrastructure Related Risk \\
\end{tabular} & $0,00 \%$ & $0,00 \%$ & $22,22 \%$ & $55,56 \%$ & $22,22 \%$ & $100,00 \%$ \\
\hline & Noise & $0,00 \%$ & $9,09 \%$ & $18,18 \%$ & $45,45 \%$ & $27,27 \%$ & $100,00 \%$ \\
\hline & Vibration & $0,00 \%$ & $0,00 \%$ & $\mathbf{0 , 0 0} \%$ & $50,00 \%$ & $50,00 \%$ & $100,00 \%$ \\
\hline \multirow{4}{*}{$\begin{array}{c}\text { RISKS RELATED TO } \\
\text { MINING } \\
\text { OPERATIONS }\end{array}$} & Blasting Works & $0,00 \%$ & $31,25 \%$ & $25,00 \%$ & $25,00 \%$ & $18,75 \%$ & $100,00 \%$ \\
\hline & \begin{tabular}{|l|} 
Ventilation and Air Condition \\
\end{tabular} & $0,00 \%$ & $15,79 \%$ & $26,32 \%$ & $47,37 \%$ & $10,53 \%$ & $100,00 \%$ \\
\hline & Machinery & $0,00 \%$ & $22,22 \%$ & $33,33 \%$ & $44,44 \%$ & $0,00 \%$ & $100,00 \%$ \\
\hline & Dust & $0,00 \%$ & $0,00 \%$ & $50,00 \%$ & $50,00 \%$ & $0,00 \%$ & $100,00 \%$ \\
\hline \multirow{4}{*}{ OTHER } & Economic & $0,00 \%$ & $0,00 \%$ & $13,33 \%$ & $26,67 \%$ & $60,00 \%$ & $100,00 \%$ \\
\hline & Social & $0,00 \%$ & $\mathbf{0 , 0 0 \%}$ & $8,33 \%$ & $41,67 \%$ & $50,00 \%$ & $100,00 \%$ \\
\hline & Political Risk & $0,00 \%$ & $12,50 \%$ & $0,00 \%$ & $25,00 \%$ & $62,50 \%$ & $100,00 \%$ \\
\hline & Pollution & $0,00 \%$ & $\mathbf{0 , 0 0 \%}$ & $0,00 \%$ & $30,00 \%$ & $70,00 \%$ & $100,00 \%$ \\
\hline
\end{tabular}

Fig. 7. Summary of the intensity of identified risks for all defined risk categories

As expected, the highest risk (Serious) is associated with problems in maintaining the stability of underground workings as well as with induced seismic activity. Based on the collected data, it was concluded that in the Seismic Activity category as much as $40 \%$ of events involves a serious risk of an accident. Similar conclusions apply in the case of hazards related to Ground Control, where $24 \%$ of events were classified as serious. The reason for this is the high level of consequences, e.g., loss of life or serious damage to the infrastructure of underground workings. This is a clear alert confirming that the risk assessment should be always carried out at the design stage of underground laboratories e.g. with the use of numerical tools. In addition, due to the nature of the environment surrounding ULs, the numerical analysis should also precede all significant changes in the geometry of a facility.

For facilities located near the seismic zones, besides calculations under static loading conditions, dynamic analyses using numerical modelling are also strongly recommended (after high energy tremors mainly). It can then minimise the possibility of workings stability and roof falls. A similar problem applies to laboratories in the vicinity of active mining operations where blasting works are being carried out (Yang et al. 2018). Induced seismic waves can have a negative impact on the stability of the rock mass surrounding the facility. It was also observed that there is a serious risk associated with the machinery movement within underground workings. This is linked to large machine dimensions and low visibility inside the cabin. The risks in this category should therefore be determined using the so-called incident rates. In case of lack of sufficient data, the risk matrix method should be used. For the remaining 14 categories, it was observed that most of the hazards were associated with medium to low risk, most often not resulting in a serious threat to health or life. However, these hazards must be continuously monitored and a number of preventive measures must be taken. It allows to obtain necessary data, and in case of emergency, to prevent or eliminate these risks. 
For events with low or acceptable risk, the risk matrix method should be used for periodic evaluation.

\section{UNIFICATION OF THE RISK ASSESSMENT PROCEDURES FOR ULs}

Based on authors, experience and surveys with ULs supervisors, a flow chart describing the risk assessment procedure in underground facilities were developed. As shown in Fig. 8, the whole process should begin with identifying the hazard and adding it to the database.

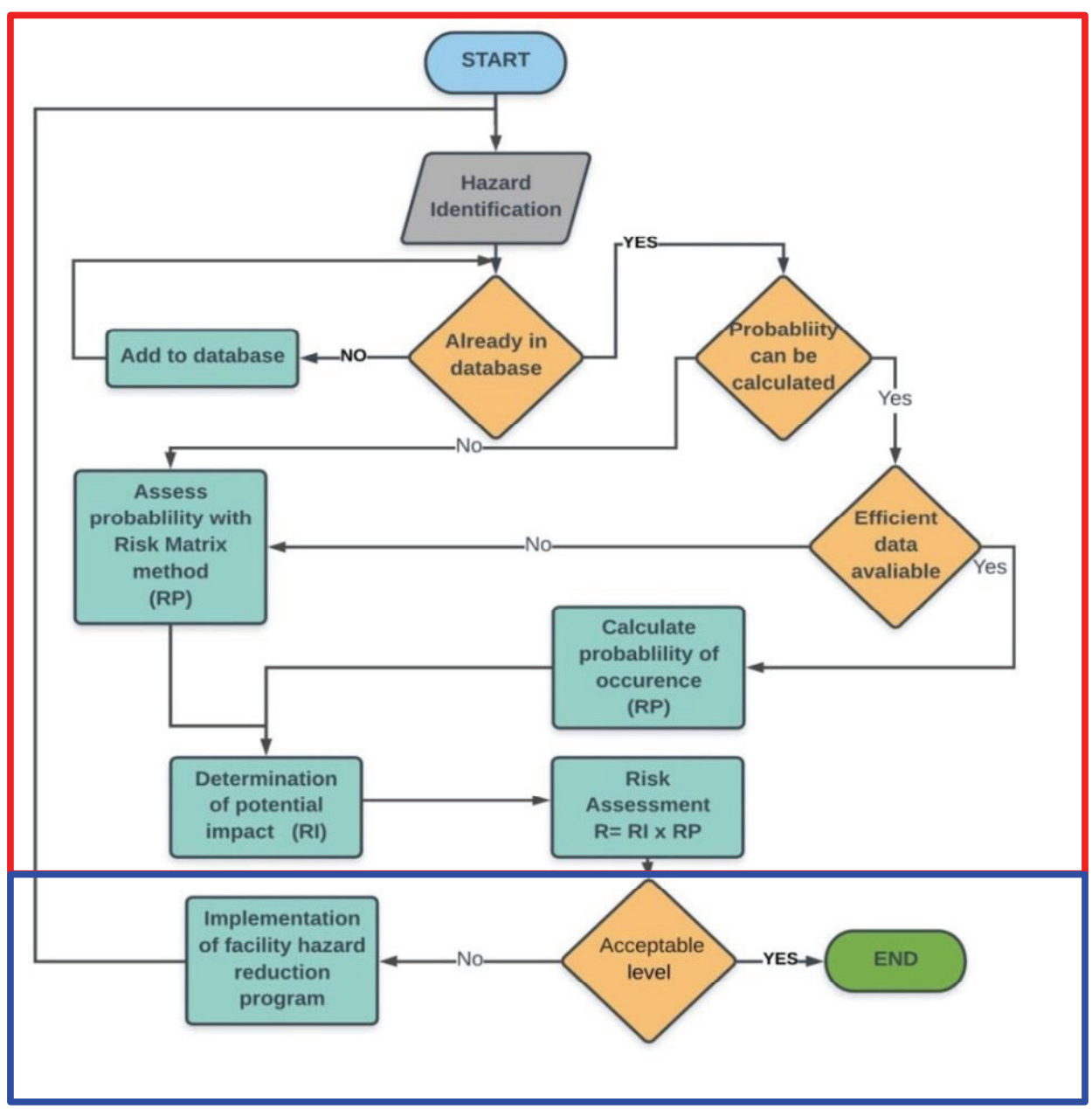

Fig. 8. Flowchart of a risk evaluation process for Underground Facilities 
After defining of each possible risk it is possible to move on to a second stage, which involves determining the possibility to calculate the probability of the unwanted event occurrence based on data collected in the past, or on results of numerical analyses. If the data cannot be presented in a numerical form, the risk matrix method should be used. The expected consequences of the dangerous incident may then be estimated. These consequences may be quantified as dimensionless or, if possible, presented as costs of compensation the consequences of an unwanted event. The last step in the process of risk assessment is to check whether the level of risk is acceptable. If not, preventive or mitigation action must be undertaken, and the risk assessment procedure shall be repeated. As can be seen in the flow chart (Fig. 8), particular emphasis was placed on the universality of the proposed solution. This paper focuses on the elements between START and RISK ASSESSMENT fields (red frame), i.e., concerning strictly the risk assessment in underground laboratories. Nevertheless, an important element of the created diagram is the decision area which qualifies individual risks as acceptable or not (blue box). If a risk is too high, it is necessary to develop and implement preventive measures to minimise the hazard. Further work on this issue will be carried out and published.

\section{CONCLUSIONS}

The article presents selected results of research work concerning the unification of procedures, which may be used for risk identifying and assessment in underground laboratories. Information on possible hazards in underground laboratories located in the Baltic Sea Region was supplemented with the summary on hazards occurring in Polish deep underground mines. As a result, a database of 106 types of the hazard was created. Based on the analysis of the collected data, it was concluded that the risks occurring in underground workings, from point of view of their origin, can be attributed into one of 18 categories classified in the four groups, i.e., Environmental Risks, Risk At The Workplace, Risks Related To Mining Operations and Other Risk. The preliminary risk assessment was then performed based on the risk matrix, which enables the definition of events causing a higher level of threat. According to conducted surveys, in case of Underground Laboratories, most dangerous events are related to ground control issues, ventilation and induced seismic activity as well. Also, machinery and transport in underground conditions may lead to harmful events occurrence. Therefore, in the case of adaption of underground space for long term use, e.g., underground Laboratory, these risk should be evaluated and if necessary mitigated at first stages. Rest of risk related to $\mathrm{H} \& \mathrm{~S}$ in underground conditions, should not bring tragic consequences, nevertheless, their impact and probability have to be assessed before running up with works on-site.

International cooperation within the created network of underground laboratories has allowed developing a procedure for estimating the level of risk in underground 
laboratories. The proposed solution is universal and can be used not only in for existing laboratories but may also be adaptable to facilities in the planning phase. Preliminary risk analysis with the use of developed risk evaluation flow chart may be also already useful during the application phase with the mining authorities. Detailed knowledge about possible treats allows preparing a mitigation plan, which makes the whole project more approachable and fulfil requirements of the EU in terms of CSR and Sustainability.

The database of possible unwanted events and their categorisation will be made available on an open platform, which in turn will be the basis for the risk management by users of underground research infrastructures and further work on the exchange of experiences related to the operation of ULs.

The presented research is the first step in the creation of a publicly available online tool for preliminary risk assessment for users and managers of underground facilities. All gathered data, risk assessment questionnaire and developed methods of risk mitigation will be available in open access at the web-based tool of Baltis Sea Underground Innovation Network founded within the framework of Interreg BSR programme.

\section{ACKNOWLEDGEMENTS}

This paper has been prepared through the Interreg Baltic Sea EU funded project on "Baltic Sea Underground Innovation Network" (BSUIN) Grant Agreement No. R2.073 (http://bsuin.eu/).

\section{REFERENCES}

AVEN T., 2010, On how to define, understand and describe risk, Reliability Engineering and System Safety, 2010, Vol. 95 (6), pp. 623-631, https://doi.org/10.1016/j.ress.2010.01.011

CICHOŃ-WALCZYK M., 2012, The method of reporting work-related incidents used in Orica as part of preventive health and safety in the workplace, Prace Naukowe Instytutu Górnictwa Politechniki Wrocławskiej $\mathrm{Nr} 134$ (41), pp. 43-53.

CLEMENS P.L., SIMMONS R.J., 1998, System Safety and Risk Management, NIOSH Instructional Module, A guide for Engineering Educators, Cincinnati.

CLIFTON A., ERICSON II, 2015, Hazard Analysis Techniques for System Safety, 2nd Edition, 2015, ISBN: 978-1-118-94038-9.

CURTIS P., CAREY M., 2012, Risk Assessment in Practice. Deloitte \& Touche LLP.

DHILLON B.S., 2010, Mine Safety A Modern Approach - Global Mine Accidents. In: Mine Safety, Springer Series in Reliability Engineering, pp. 59-71, DOI: 10.1007/978-1-84996-115-8.

DUMBRAVĂ V., VLĂDUȚ-SEVERIAN I., 2013, Economics and Information Technology Using Probability - Impact Matrix in Analysis and Risk Assessment Project, Journal of Knowledge Management, 2013, Special Issue, December, pp. 76-96.

FENTON G.A., GRIFFITHS D.V., 2008, Risk assessment in geotechnical engineering, John Wiley \& Sons, Inc., New Jersey, DOI: 10.1002/9780470284704.

FUŁAWKA K., PYTEL W., MERTUSZKA P., 2018, The effect of selected rockburst prevention measures on seismic activity - Case study from the Rudna copper mine, Journal of Sustainable Mining, Vol. 17, pp. 1-10, https://doi.org/10.1016/j.jsm.2018.03.001 
GALVIN J., 2017, Critical role of risk management in ground engineering and opportunities for improvement, International Journal of Mining Science and Technology, Vol. 27 (5), pp. 725-731, ISSN 2095-2686, https://doi.org/10.1016/j.ijmst.2017.07.005

GHORBANI S., NAMIN F.S., LAJEVARDI S.A., 2017, A Statistical-Probabilistic Pattern for Determination of Tunnel Advance Step by Quantitative Risk Analysis, Int. Journal of Mining and Geoengineering, 2017, Vol. 51 (2), pp. 161-176, DOI: 10.22059/IJMGE.2017.230636.594663.

GROVES W.A., KECOJEVIC V.J., KOMLJENOVIC D., 2007, Analysis of fatalities and injuries involving mining equipment, Journal of Safety Research, Vol. 38 (4), pp. 461-470, ISSN 0022-4375, https://doi.org/10.1016/j.jsr.2007.03.011

IDRIS M.A., SAIANGAND D., NORDLUND E., 2011, Probabilistic analysis of open stope stability using numerical modelling, Int. J. Mining and Mineral Engineering, Vol. 3 (3), pp. 194-219, https:// doi.org/10.1504/IJMME.2011.043849

IEC 31010:2009 - Risk management - Risk assessment techniques.

IEC 60812, Edition 2.0 2006-01, Analysis techniques for system reliability - Procedure for failure mode and effects analysis (FMECA).

ISO Guide 73:2009, Risk management - Vocabulary.

KENNETH J. ROTHMAN, 2002, Epidemiology - An Introduction, Oxford University Press, pp. 34-36.

KOMLJENOVIC D., GROVES W.A., KECOJEVIC V.J., 2008, Injuries in U.S. mining operations - A preliminary risk analysis, Safety Science, Vol. 46 (5), pp. 792-801, ISSN 0925-7535, https://doi.org/ 10.1016/j.ssci.2007.01.012

LI T., CAI M.F., CAI M., 2007, A review of mining-induced seismicity in China, International Journal of Rock Mechanics and Mining Sciences, Vol. 44 (8), pp. 1149-1171.

MARTYKA J., 2015, Stan kultury bezpieczeństwa dozoru Zakładów Górniczych KGHM Polska Miedź S.A. oraz program doskonalenia kultury bezpieczeństwa załóg górniczych (Safety culture state of supervision in mining plant of KGHM Polska Miedź S.A. and program to improve safety culture of mining Staff), CUPRUM - Czasopismo Naukowo-Techniczne Górnictwa Rud, 2015, Vol. 3 (76), pp. 233-251.

PARK H.J., WEST T.R., WOO I., 2005, Probabilistic analysis of rock slope stability and random properties of discontinuity parameters, Interstate Highway 40, Western North Carolina, USA, Engineering Geology, Vol. 79 (3-4), pp. 230-250, https://doi.org/10.1016/j.enggeo.2005.02.001

Project Management Institute 2013, Inc., A Guide to the Project Management Body of Knowledge (PMBOK ${ }^{\mathbb{R}}$ Guide) - Fifth Ed., 2013, Project Management Institute, Inc., Newtown Square, Pennsylvania.

RADU L.D., 2009, Qualitative, Semi-Quantitative and Quantitative Methods for Risk Assessment: Case of the Financial Audit, Analele Stiintifice ale Universitatii "Alexandru Ioan Cuza" din Iasi - Stiinte Economice, Vol. 56, pp, 643-657.

RocScience - Probabilistic Analysis in RS2, 2018.

SANMIQUEL L., FREIJO M., EDO J., ROSSELL J.M., 2010, Analysis of work related accidents in the Spanish mining sector from 1982-2006, Journal of Safety Research, Vol. 41 (1), pp. 1-7, ISSN 0022-4375, https://doi.org/10.1016/j.jsr.2009.09.008

SHOOKS M., JOHANSSON B., ANDERSSON E., LÖÖW J., 2014, Safety and Health in European Mining - A report on safety and health, statistics, tools and laws, produced for the I2 Mine (Innovative Technologies and Concepts for the Intelligent Deep Mine of the Future) project, Division of Human Work Science, Skandinaviens nordligaste tekniska universitet Forskning \& utbildning i världsklass, pp. 3-10.

SMOLARKIEWICZ M., SMOLARKIEWICZ M.M., BIEDUGNIS S., 2011, Matrix methods for risk management - Associated Matrices Theory, Środkowo-Pomorskie Towarzystwo Naukowe Ochrony Środowiska, Vol. 13. pp. 241-252.

SUDDLE S., 2009, The weighted risk analysis, Safety Science, Vol. 47 (5), pp. 668-679, DOI: 10.1016/ j.ssci.2008.09.005. 
SZURGACZ D., 2015, Numerical analysis for an optimization of a powered roof support operating in hazard conidtions of minig tremors, Mining Science, Vol. 22, pp. 171-179.

UNISDR, 2004, Living with risk - a global review of disaster reduction initiatives.

VARDAR O., ZHANG C., CANBULAT I., HEBBLEWHITE B., 2018, A semi-quantitative coal burst risk classification system, International Journal of Mining Science and Technology, Vol. 28 (5), pp. 721-727, ISSN 2095-2686, https://doi.org/10.1016/j.ijmst.2018.08.001

Webpage of Occupational Safety and Health Administration, https://www.osha.gov (access in 2018).

YANG C., HONGGUANG J., TIANBAO Z., 2018, Blasting control and monitoring system for safety improvement during blasting operation - a case study in guilaizhuang gold mine, Mining Science, Vol. 25, pp. 33-48, DOI: $10.5277 / \mathrm{msc} 182504$.

ZEROUAL NÉE DADOUCHE F., IAZHARB B., ZENNIRC A., 2011, Probabilistic analysis of slope stability towards the slip by the kinematic method, Physics Procedia, Vol. 21, pp. 93-100, https:// doi.org/10.1016/j.phpro.2011.10.014

ZORYCHTA A., BURTAN Z., 2012, Conditions of fault activation in the area of exploitation, AGH Journal of Mining and Geoengineering, Vol. 36 (3), pp. 509-519. 